\title{
EXTENSÃO UNIVERSITÁRIA E EDUCAÇÃO EM DOENÇAS SEXUALMENTE TRANSMISSÍVEIS E TEMAS RELACIONADOS
}

\author{
Roseane Aparecida dos Reis ALVES ${ }^{1}$ \\ Marcela FORGERINI ${ }^{2}$ \\ Ítala dos Santos e SILVA ${ }^{3}$ \\ Thaylla Albino VIEIRA ${ }^{4}$ \\ Ana Paula Garcia de LIMA ${ }^{5}$ \\ Gabriel Braulio Xavier SENA ${ }^{6}$ \\ Sandra Maria Oliveira Morais VEIGA ${ }^{7}$
}

\begin{abstract}
${ }^{1}$ Graduanda em Farmácia pela Universidade Federal de Alfenas (UNIFAL). roseanealvesfarma@ gmail.com
${ }^{2}$ Graduada em Farmácia pela Universidade Federal de Alfenas (UNIFAL). marcelinha_forgerini@ hotmail.com

${ }^{3}$ Graduanda em Farmácia pela Universidade Federal de Alfenas (UNIFAL). italasantoss@live.com

${ }^{4}$ Graduanda em Farmácia pela Universidade Federal de Alfenas (UNIFAL). thayllavieira @ gmail.com

${ }^{5}$ Graduanda em Farmácia pela Universidade Federal de Alfenas (UNIFAL). anapaulagarciadelima@ @otmail.com

${ }^{6}$ Graduando em Medicina pela Universidade Federal de Alfenas (UNIFAL). gabrielbraulio@ hotmail.com

${ }^{7}$ Doutora, Professora da Universidade Federal de Alfenas (UNIFAL). smveiga@ gmail.com
\end{abstract}

Recebido em: 21/07/2016 - Aprovado em: 21/10/2016 - Disponibilizado em: 18/12/2016

\begin{abstract}
RESUMO:
Este artigo aborda o tema Extensão Universitária e Educação em Doenças Sexualmente Transmissíveis (DST) e temas relacionados, com enfoque nas campanhas educativas organizadas pelo projeto de extensão Doenças Sexualmente Transmissíveis e Hepatites Virais da Universidade Federal de Alfenas (UNIFAL-MG). O objetivo das atividades educativas foi orientar jovens, adultos e idosos para a prevenção e controle das DST, AIDS e Hepatites Virais, bem como favorecer a multiplicação da informação sobre o tema e a troca de conhecimentos e saberes. Os assuntos abordados foram: os sinais e sintomas das DST, AIDS e Hepatites Virais, suas complicações, formas de transmissão, importância do diagnóstico precoce, tratamento, medidas de prevenção e controle e temas relacionados. O projeto elaborou também materiais educativos específicos para os diferentes públicos, tais como panfletos e cartilhas sobre DST, AIDS e Hepatites Virais, medidas de prevenção e controle, higiene íntima, câncer de mama e de próstata. Em algumas oportunidades, foi ofertado o teste rápido para Hepatite C.
\end{abstract}

Palavras-chave: Doenças Sexualmente Transmissíveis. Extensão Universitária. Educação. Saúde. Prevenção.

\section{ABSTRACT:}

This article discusses the topic University Extension and Education Sexually Transmitted Diseases (STDs) and related issues, focusing on educational campaigns organized by the extension project Sexually Transmitted Diseases and Viral Hepatitis of the Federal University of Alfenas (UNIFAL-MG). The goal of educational activities was to guide young people, adults and elderly for the prevention and control of STDs, AIDS and Viral Hepatitis and favor the proliferation of information on the issue and the exchange of knowledge and expertise. The subjects covered were the signs and symptoms of STDs, AIDS and Viral Hepatitis, complications, transmission, importance of early diagnosis, treatment, prevention and control and issues related measures. The project also developed specific educational materials for different audiences, such as pamphlets and booklets about STD, AIDS and Viral Hepatitis, prevention and control measures, intimate hygiene, breast and prostate cancer. On some occasions, we were offered the rapid test for Hepatitis C.

Keywords: Sexually Transmitted Diseases. University Extension. Education. Health. Prevention. 


\section{INTRODUÇÃO}

Segundo o Plano Nacional de Extensão Universitária (BRASIL, 2001), na Universidade, as ações de extensão são executadas por inúmeras áreas de conhecimento, onde apresentam diferentes objetos e assuntos, com enfoques distintos. Assim, os projetos de extensão universitária realizam várias atividades educativas que compõem a formação profissional dos acadêmicos, capacitando-os para atuarem na perspectiva da promoção de saúde de um modo geral na população. É de suma importância realizar essas atividades, pois é notório a relação de reciprocidade com a comunidade, onde é estabelecido uma aliança entre o saber empírico e o acadêmico, integrando a produção e a sistematização do conhecimento como um processo de aprendizagem significativo. Assim, essa interação entre os acadêmicos e a sociedade, tem papel determinante no que tange à capacidade de instigar nos indivíduos uma consciência mais crítica, quanto suas atitudes relacionadas a prevenção de inúmeras doenças, fomentando dessa maneira transformações na comunidade.

Como as DST representam um grande desafio para as autoridades de saúde e educação do mundo atual e estão presentes em todos os grupos etários e sociais, o Projeto de Extensão Doenças Sexualmente Transmissíveis e Hepatites Virais (DST/HV) da Universidade Federal de Alfenas
(UNIFAL-MG), tem o intuito de disseminar o conhecimento acadêmico e social, dando enfoque na prevenção das DST, Hepatites Virais e também em outras doenças que acometem inúmeras pessoas como o câncer de mama, colo uterino e próstata, além de orientar a população sobre a importância da higiene íntima e da realização dos exames de rotina. Assim, possibilita a integração da Universidade com a comunidade, respaldando um dentre os três pilares de uma Universidade Pública, que representa a extensão.

$\mathrm{O}$ projeto atua de forma interativa, proporcionando saberes a respeito dessas doenças, capacitando jovens, adultos e idosos para a prevenção, diagnóstico precoce e tratamento oportuno. Ainda, forma multiplicadores do conhecimento e possibilita o levantamento de dados que possam subsidiar ações futuras do referido projeto. São realizadas inúmeras atividades educacionais como: campanhas; palestras e minicursos; stands educativos; demonstrativos do aparelho reprodutor masculino e feminino; demonstração do uso correto do preservativo feminino e masculino, entre muitas outras vertentes, abrangendo diferentes faixas etárias, enfatizando, principalmente, a importância da prevenção das DST, Hepatites Virais e outras doenças.

É realizada a confecção de cartilhas para as mulheres, com informações voltadas aos cuidados do câncer de mama e colo uterino, maneira correta da higienização 
íntima e curiosidades sobre as DST e cartilhas para os homens - Novembro Azul disseminando conhecimentos sobre câncer de próstata e prevenção, com distribuição durante as campanhas, tendo um retorno satisfatório, sanando dúvidas pertinentes.

Assim, as açõesdoprojeto de extensão DST/HV da UNIFAL-MG têm grande impacto sobre a comunidade, pois dissemina conhecimentos através das suas atividades, englobando um público distinto, de forma direta e indireta (por meio de canais virtuais). Dessa maneira, embora sejam citadas todas as atividades educacionais que o projeto DST/HV executa, no presente artigo, será abordado apenas os dados obtidos em campanhas.Vale ressaltar que o Projeto DST/HV atua em consonância com as atividades realizadas pelo Ministério da Saúde, objetivando a capacitação da população para a prevenção, controle e diagnóstico precoce dessas doenças, por meio da multiplicação da informação e orientação da população.

\section{OBJETIVO}

Tornar público as atividades executadas pelo Projeto de Extensão Doenças Sexualmente Transmissíveis e Hepatites Virais, que são realizadas pelos discentes da UNIFAL-MG, difundindo conhecimento sobre essas doenças e temas relacionados, com enfoque na prevenção, controle e diagnóstico precoce.

\section{MATERIAS E MÉTODOS}

\section{Materiais}

O projeto organiza campanhas educativas para a comunidade acadêmica e externa, por meio de stands interativos, com distribuição de material e cartilhas informativas, com discussão de dúvidas e multiplicação da informação.

\section{Métodos}

Os temas trabalhados com a comunidade durante as campanhas educativas abordaram as DST, AIDS, Hepatites Virais, complicações destas doenças, suas formas de transmissão, medidas de prevenção (incluindo o uso correto do preservativo feminino e masculino e as vacinas contra Hepatite B e HPV), além da importância do diagnóstico precoce e posterior tratamento. Saúde da mulher e do homem também foram debatidos, como a higiene íntima, prevenção e diagnóstico precoce dos tumores de mama, colo uterino e próstata, ressaltando a importância do exame preventivo do câncer de colo uterino, exame clínico das mamas, mamografia e do exame de próstata.

A equipe do projeto desenvolve o material informativo de acordo com a campanha que será realizada, atendendo a demandas da população.

O público é orientado sobre os testes sorológicos rápidos de Súfilis, Hepatites B e C, HIV, ambos gratuitos e sigilosos, que podem ser realizados no Centro de Testagem 
e Aconselhamento de Alfenas (CTA), local que também disponibiliza suporte médico e psicossocial.

Nas campanhas é ofertado para a população a possibilidade de realizar a sorologia rápida para Hepatite $\mathrm{C}$ (Teste Rápido OL HCV). Os testes reagentes são encaminhados ao CTA para teste confirmatório, tratamento e aconselhamento ao indivíduo.

O projeto disponibiliza também, o $B L O G$ (http://dstaidsunifal.blogspot.com.br/) e o perfil na rede social Facebook (Saúde DST), ferramentas online intensamente divulgadas nas ações, os quais são rotineiramente atualizados com informativos e esclarecem as dúvidas anônimas enviadas pelos leitores.

\section{RESULTADOS E DISCUSSÕES}

\section{ATIVIDADES DESENVOLVIDAS}

O projeto trabalhou diretamente com 2.701 pessoas por meio das campanhas educativas realizadas nos anos de 2014 e 2015.

\section{Campanhas educativas}

Uso Racional de Medicamentos (URM): 350 pessoas

Foi realizada pelo Centro Acadêmico de Farmácia da UNIFAL-MG (CAFAR), atuando na prevenção e controle das DST e
Hepatites Virais e no tratamento, com ênfase no uso racional da medicação, na adesão ao tratamento, e orientação sobre as reações adversas.

Parcerias com instituições e com eventos permitem atingir um público mais abrangente, atuando com diversas faixas etárias e sociais.

\section{Dia dos Namorados: 628 acadêmicos da UNIFAL-MG}

Realizada para os acadêmicos da UNIFAL-MG, Campus Sede, onde foram distribuídos panfletos, preservativos femininos e masculinos, além das orientações sobre as DST e demonstração do uso correto do preservativo feminino.

Foi confeccionada uma cartilha: 'Mitos e Verdades' para distribuição, quebrando tabus da sexualidade e as principais dúvidas relacionadas com a transmissão das DST, o sexo seguro e as formas de prevenção.

\section{Semana Nacional do Idoso: 87 idosos}

A equipe do projeto organizou e proferiu uma Palestra Motivacional e Educativa para a UNATI (Universidade Aberta a Terceira Idade), com o stand educativo e distribuição da cartilha formulada 'Saúde do Homem e da Mulher', com discussão de uma boa qualidade de vida, câncer de mama, colo uterino e próstata, enfatizando a importância da informação e prevenção. 
Acolhida aos Calouros da UNIFAL-MG: 400 acadêmicos

Stand educativo no evento de Acolhida aos Calouros, apresentando o projeto e suas atividades para a comunidade acadêmica, além da distribuição de material educativo e divulgação do CTA.

\section{Dia do Servidor Público: 250 servidores}

A campanha foi realizada para os servidores públicos da UNIFAL-MG, com distribuição de material educativo, preservativos e discussão das dúvidas apresentadas.

Dia Mundial de Luta Contra a AIDS: 611 pessoas

Foi realizada para a comunidade acadêmica da UNIFAL-MG e para os pacientes de uma Unidade Básica de Saúde (IBS) em Alfenas, enfatizando as formas de transmissão do HIV, a importância do diagnóstico precoce, os avanços nos estudos do tratamento da AIDS e a minimização do preconceito.

\section{Dia Internacional da Mulher: 100 mulheres}

Houve distribuição da cartilha de autoria dos integrantes do projeto, em comemoração ao dia das mulheres, abordando temas como HPV, câncer de colo de útero e o exame preventivo de colo de útero; prevenção do câncer de mama e o autoexame, candidíase, higiene íntima e o uso correto do sabonete íntimo e do preservativo feminino.

É notório o desconhecimento em relação à existência e a maneira correta de utilização do preservativo feminino, principalmente por parte das mulheres, o que ressalta a importância das ações realizadas e a falta de informação da comunidade.

Assim, as ações baseiam-se na metodologia participativa, com a demonstração do preservativo feminino e levantamento das dúvidas em relação à saúde da mulher, tanto sobre as práticas sexuais, quanto sobre o funcionamento do aparelho reprodutor feminino.

\section{Dia Mundial da Saúde: 75 pessoas acadêmicos}

Stand educativo com distribuição de informativos sobre as DST, seus sinais e sintomas clínico, a importância do diagnóstico precoce e o câncer de mama.

Assim, Segundo Nascimento, 2012, "As campanhas preventivas de saúde têm como objetivo principal promover a saúde, estimulando a mudança de comportamento para hábitos mais saudáveis e consequentemente prevenindo de doenças". Dessa forma, é importante que as campanhas sejam apresentadas de forma clara e objetiva, utilizando-se de termos que possam ser compreendidos pelo público alvo e que desperte a atenção deste. 


\section{Testes Sorológicos}

Ao todo o Projeto realizou 200 testes rápidos para Hepatite $\mathrm{C}$, incluindo jovens, adultos, idosos e manicures. Detectaram-se dois testes reagentes, os quais foram encaminhados para o CTA para realização de uma triagem mais completa para a confirmação do resultado e acompanhamento do paciente.

Assim, é notória a importância das atividades da extensão universitária, principalmente em temas com impacto direto na população, como promoção da saúde e a prevenção de DST/AIDS e Hepatites Virais, pois ainda é observada a existência de muitos tabus e preconceitos nos temas relacionados à sexualidade. Por outro lado, inúmeros são os esforços de diferentes instituições no sentido de conscientizar jovens e adultos sobre a vulnerabilidade às DST/HIV/AIDS e da necessidade de ações para preveni-las (SIPPERT; SAND, 2004).

Portanto, diversas atividades são realizadas por Universidades brasileiras, com o intuito comum de disseminar conhecimento das DST e preveni-las da forma correta. Diferentes metodologias são utilizadas para abordar o público alvo, desde campanhas abertas à comunidade, palestras, oficinas e dinâmicas, contribuindo assim no objetivo único, no processo de educação sexual, para que todas as faixas etárias e sociais possam ter informações confiáveis e uma vida mais saudável e de qualidade.
Ressaltamos que este projeto atuou em consonância com o Departamento de DST, AIDS e Hepatites Virais do Ministério da Saúde, que têm como objetivos reduzir a transmissão do HIV/AIDS, Hepatites Virais e das Doenças Sexualmente Transmissíveis, visando o aumento da qualidade de vida das pessoas portadoras de alguma DST (BRASIL, 2016). Este Departamento atua por meio do fortalecimento da rede de atenção e linhas de cuidado às DST, AIDS e Hepatites Virais; da prevenção, diagnóstico precoce da infecção pelo HIV e Hepatites Virais, de ações de saúde para redução do risco e da vulnerabilidade, incluindo o acesso universal aos medicamentos, preservativos e outros insumos estratégicos (BRASIL, 2016).

Os Centros de Testagem e Aconselhamento (CTA) estão dentre alguns serviços de saúde oferecidos pelo Departamento de DST, AIDS e Hepatites Virais, onde são realizadas ações de diagnóstico e prevenção de DST. Possuem uma unidade em quase todas as regiões do país, incluindo na cidade de Alfenas - MG, onde atuam e realizam testes gratuitos para HIV, sífilis e hepatites B e C, além de fornecerem para a população de forma gratuita, insumos de prevenção como camisinhas masculinas e femininas, lubrificantes, além de kits de redução de danos para pessoas que fazem uso de drogas.

$\mathrm{O}$ atendimento ocorre de forma sigilosa e a pessoa tem a opção de ser acompanhado 
por uma equipe de saúde, recebendo informações e orientações, independentemente de ser portador ou não de alguma DST. Portanto, o CTA é uma importante ferramenta de apoio à saúde do indivíduo, mas que antes de tudo faz-se necessário sua divulgação nos diferentes meios de comunicação.

O CTA de Alfenas relatou que, após o início da parceria com o Projeto DST/HV, houve um aumento significativo da busca populacional pelos serviços ofertados pelo centro, pois é realizada a constante divulgação do CTA em todas as atividades educativas, informando sobre $\mathrm{o}$ atendimento $\mathrm{e}$ testes realizados. Logo, compreende-se que o Projeto é um fomentador de mudanças de comportamento, uma vez que, estimula à população a agir buscando mais qualidade de vida, saúde e informação.

Além da atuação em conjunto com as ações do Ministério da Saúde, é desenvolvido outras campanhas temáticas, de acordo com a necessidade da comunidade.

\section{CONCLUSÃO}

As campanhas contribuíram de forma fundamental no incentivo à responsabilidade da sociedade para com a sua própria saúde e para com a saúde do parceiro.

$\mathrm{O}$ projeto contribui para a ampliação do conhecimento sobre o tema e suas vertentes, para o aumento do conhecimento sobre as Doenças Sexualmente
Transmissíveis, HIV/AIDS, Hepatites Virais, e temas relacionados a sexualidade, favorecendo a promoção, proteção e recuperação da saúde de vários participantes. Ainda, para a formação de multiplicadores do conhecimento.

Atividades de extensão, tais como as desenvolvidas pelo projeto DST/HV, devem ser realizadas continuamente, por acadêmicos e docentes das diversas Universidades no território nacional.Proporcionando ainda a formação técnica, cientifica, ética, cidadã e humanista de toda equipe participante.

\section{REFERÊNCIAS}

BRASIL. Ministério da Saúde. Promoção da Saúde: declaração de Alma-Ata: 1978, Carta de Ottawa, declaração de Sundsvall. Brasília (DF); 2001.

BRASIL. Ministério da Saúde. Portal sobre aids, doenças sexualmente transmissíveis e hepatites virais. Disponível em: http://www.aids.gov.br/. Acesso em 15 de abril de 2016.

BRASIL. Ministério da Saúde. Portal da Saúde. Disponível em:

http://portalsaude.saude.gov.br/index.php/cidada o/principal/campanhas-publicitarias. Acesso em 15 de abril de 2016.

NASCIMENTO, S.L. O impacto das campanhas de DST/AIDS no comportamento sexual dos adolescentes. 2012. 59f. Trabalho final de curso (Bacharel) Faculdade de Ceilândia, Universidade de Brasília, Brasília-DF, 2012.

SIPPERT, N.; SAND, I. C. P. V. D.

Conhecimento de estudantes de escolas inseridas no projeto "encontro" do centro de atendimento ao adolescente do município de ijuí, sobre 
DST/HIV/AIDS. Revista contexto \& saúde.

Editora Unijuí, n. 06, jan./jun. 2004, p. 43-62.

Agradecimento aos parceiros

- CTA -Centro de Testagem e Aconselhamento de Alfenas (Instituição governamental municipal).

- CAFAR - Centro Acadêmico da Farmácia (Organização estudantil). 